\title{
Theory about University Disciplines Setup And the Demand of the Beibu Gulf Economic Zone in Guangxi
}

\author{
Guiyuan HUANG \\ Qinzhou University \\ Qinzhou, Guangxi 535099, China
}

\begin{abstract}
The development of the Beibu Gulf Economic Zone is one of the national development strategy, the development of the economic zone needs a large number of applied and innovative talents. Colleges and universities in Guangxi Beibu Gulf Economic Zone of personnel training and the main force of the main front shoulder area of the economy and transport a large number of training applied talents of the task. However, there remain current personnel training problems in the Beibu Gulf Economic Zone. For example, construction discipline lags and students innovative teaching practice is not strong, inadequate investment and other issues. To this end, Guangxi universities should actively explore effective measures to continuously improve the quality of talents training, provide strong poll and intellectual support for the development of the economic zone.
\end{abstract}

Keywords- Guangxi Beibu Gulf Economic Zone; Applied Talents; Guangxi Universities; Problems; Countermeasures

\section{INTRODUCTION}

January 16, 2008, the state approved the implementation of the "Guangxi Beibu Gulf Economic Zone Development Plan." Development of Beibu Gulf Economic Zone must rely on the talent for protection, Guangxi Beibu Gulf Economic Zone as college personnel training the main front and force, it should take the initiative to assume economic zone training and delivery of a large number of application-oriented talents task. However, there are still many problems in Guangxi Universities in the Beibu Gulf Economic Zone about the training of personnel. We have to study these issues as soon as possible to find countermeasures, so as to comprehensively improve the quality of personnel training to meet the actual needs of the development of the economic zone to a maximum extent. First, the Beibu Gulf Economic Zone is characterized by its talent strategy. Guangxi Beibu Gulf Economic Zone is located in the southwestern tip of China's coastal regions, mainly by Nanning, Beihai, Qinzhou, Fangchenggang four cities and Yulin, Chongzuo Municipal logistics center "4 +2 " administrative region under the jurisdiction of the composition. According to the "Guangxi Beibu Gulf Economic Zone Development Plan", the economic zone will be built into China - ASEAN cooperation open logistics base, business base, manufacturing base and information exchange center, a drive, supporting strategic highland western development and opening up high radiation and strong, economic prosperity, social harmony, good ecological importance of international economic cooperation zone. Economic zone will focus on the development of petrochemical, pulp and paper, energy, steel, aluminum, foodstuff processing, marine industry, hightech, logistics and modern service industry and other nine. Currently, the economic zone infrastructure construction has made significant progress in the North Bay, the coastal port handling capacity of over 50 million tons, collection and distribution conditions gradually improved, played a role in the southwest passage to the sea.

\section{Current Problems Exist In Mode OF Personnel TRAINING IN GUANGXI UNIVERSITY}

The main problems are the institutional problems that currently exist in conceptual issues of personnel training and personnel training.

Training targets are unclear. When objectives position of personnel training of Guangxi University are unclear, opening up and development in Guangxi Beibu Gulf Economic Zone became a national development strategy, no keen to consider the needs of national and social development. There is no consideration in improving the socialist market economic system in the process, Guangxi Beibu Gulf Economic zone adjustment of industrial structure and employment structure, without considering the social requirements of general practitioners to improve the overall quality of talent demand trends and trend of diversification, to adjust their training objectives. Targeting personnel training does not meet the demand for quality talent. Previous training objectives are high enough, and do not pay attention to the quality of education of talent, lack of talent innovative consciousness and ability requirements. The requirement of lifelong learning is not enough. Such as Guangxi University to train high-quality, innovative talent as a fundamental objective, according to the "wide caliber, thick foundation, high-quality, ability," the personnel training requirements, and constantly promote educational reform. Guangxi University of Finance aims at cultivating the learning ability, practical ability, continuous innovation and entrepreneurial spirit of innovative talents. On the training objectives have not positioned as applied talents, lack of ideas for local economic development services.

III. NeCESSity OF COLLEGE TALENT TRAINING ModE

GUANGXI BEIBU GULF ECONOMIC ZONE DEVELOPMENT

ADAPTATION UNDER CHINA'S NATIONAL DEVELOPMENT AND REFORM COMMISSION

January 16, 2008 approved the "Guangxi Beibu Gulf Economic Zone Development Plan", opening up and 
development of Guangxi Beibu Gulf Economic Zone formally incorporated into national development strategies. Guangxi Beibu Gulf Economic Zone will be built into an important international and regional economic cooperation Zone. Guangxi Beibu Gulf Economic Zone function defined as: based on the North Bay, serving the Southwest, South, Central, communicate three regions, for Southeast Asia, giving full play to the important area of multi-channel connection, communication and collaboration platform for the bridge to open cooperation for development and construction, --- ASEAN efforts to build China's logistics base open cooperation, business base, manufacturing base and information exchange center, a drive, a high degree of strategic high ground and open support of the western development, radiation and strong, economic prosperity, social harmony, ecological good important international and regional cooperation zones. 2. The necessity of research. According to the "Guangxi Beibu Gulf Economic Zone Development Plan" and related industrial planning, talent development combined with practical and industry characteristics Economic Zone in Guangxi preparation of the "Guangxi Beibu Gulf Economic Zone Development Plan 2008-2015 Talent", focusing on determining the petrochemical, pulp forest paper, energy, steel and aluminum, foodstuff processing, marine industry, high-tech, logistics, and focus on the development of modern service industry and other nine. It is predicted that by 2010, total demand for talent in Guangxi Beibu Gulf Economic Zone will reach 115 million in 2015, total personnel will reach 168 million people. However, the relative lack of Guangxi also has an international perspective, familiar with international rules and practices, to participate effectively in international export-oriented high-level talent competition; the lack of much-needed development of coastal industrial petrochemical, steel, power, finance, and tourism and other industry professionals and highly skilled personnel.

\section{UNIVERSITIES INVOLVED IN THE STRATEGIC CHOICE OF GUANGXI BEIBU GULF ECONOMIC ZONE MARINE ECONOMIC DEVELOPMENT}

From the perspective of strategic management perspective, Guangxi universities want to fully understand the basis of their own advantages, personnel training and technological innovation, as a strategic entry point to take effective measures to participate in the strategic Gulf Economic Zone marine economic development. In this, the author of Guangxi University, for example, around the universities involved in the strategic game problem Guangxi Beibu Gulf Economic Zone marine economic development, superficial discussion for the following areas: platform strategy is defined according to the advantages of traditional disciplines and universities, in colleges and universities Creating and marine economy respective disciplines and these disciplines together to form into a college or department, serving as a strategic platform for marine economy, through an integrated platform scale cultivation of marine resources in the economic advantages of talent around the marine economy technological problems arising carry out large team-based science and technology research.
This feature of the strategy is to scale, the Group and integration. For example, aquatic disciplines Guangxi University is a school with 38-year-old disciplines, Guangxi University and the marine economy is relatively close disciplines. The disciplines to form the basis of marine aquaculture, processing and trade as the main body of the Maritime Academy to college as a direct service to the Beibu Gulf Economic Zone in Guangxi marine economic development platform, which is indeed the most effective measures of platform strategy.

Training based on the community needs to emphasize, highlight the "thick foundation, wide caliber and innovation" through Combination of training personnel on the target. Such as Zhejiang University that "comprehensive university agronomy compound talents training mode," Tsinghua University "Polytechnic Cross compound innovative training model", "science and engineering disciplines innovative training model" Tianjin University. They extensively emphasize on strengthening students' basics of education, the formation of wide caliber, focusing on cultivating students' creative ability and to lay a solid foundation for the subsequent development of the students. The basic idea is to conduct unified foundation teaching, including the general education curriculum and academic foundation courses, hobbies and social needs and then split according to students' interests. Secondly, it widely emphasizes on setting of basic theoretical courses on curriculum, intensive courses organized modules or curriculum, open electives. Zhejiang University proposed "comprehensive university agronomy compound talents training mode", the pre-established platform for strengthening basic foundation courses, post additional professional module, elective credits and personalized curriculum; Inner Mongolia University's "Mathematical Cross compound talents training mode." The basic design principle is to strengthen the basic curriculum, the formation of modular curriculum system, relying on discipline group cultivate innovative talents.

\section{POLICY RECOMMENDATION ABOUT TALENTS IN GUANGXI HIGHER EDUCATION AND UNIVERSITY DEVELOPMENT}

\section{A. Concept First}

Social value of education is not proved by itself. It can only be confirmed in order to promote social development by meeting the needs of the community. Therefore, accurately reflect the needs of the community for education; good education is in accordance with the needs of society, which is to promote the development of education only the right path. Moreover, with the development of higher quality, from a historical perspective of the development of higher education, different stages of development of higher education have different specifications, with a sense of the quality of elite education to Mass Education Stage treatise, or popularity View of the quality of education to regulate the quality of elite education, they are not desirable. Therefore, whether the student, the employer, or the government, should not be limited by a single quality of higher education, we 
should establish a variety of talent, quality concept, in order to accurately reflect the needs of society, and promote economic development. Based on the original, the government in dealing with the basis of the poor colleges, private colleges and universities on the issue, can provide more policy support, guide and encourage the macro, which is conducive to the formation of a multi-species, multistandard, education which includes all systems operating together.

\section{B. Policy Guidance}

May 29, 2008, the State Council approved the establishment of Qinzhou Bonded Port Area, which is the first bonded port Midwest. Establishment of Qinzhou Bonded Port is the CPC Central Committee and the State Council to support the development of the Beibu Gulf Economic Zone is another major initiative that is a milestone in the development of open economic zone, marking the opening up and development of Beibu Gulf Economic Zone in Guangxi substantive breakthrough. This will undoubtedly have a significant and far-reaching significance for the development of Guangxi and even open cooperation between China and ASEAN countries.

Determining a school and professional training mode is not subjective, arbitrary choice, but faced with the dual constraints of social needs and their own conditions. This constraint actually gave training model selection principles which should be followed: First, in line with the principles of economic and social development, it needs of the Beibu Gulf Economic Zone. Cultivating a certain training model out whether students meet local community needs, whether the employer is willing to accept the inspection of the training model of the most important success criteria. Therefore, economic and social development of Guangxi Beibu Gulf Economic Zone has become required to select Training Mode important "pointer", you can say, select Training Mode overriding principle is to meet the needs of local economic and social development. Second, follow the principle of contradiction particularity. Social needs are unique, which determine the training objectives of the market can be subdivided. But the personnel training determines which one or what kinds of target market segments talent is, as well as what kind of training methods we use. However, it depends on the capability and the future and strives to achieve their own school conditions. This requires training model selection and should follow the local conditions to analyze specific issues of principle. For example, as the high school level, Guangxi University, has a long history, strong teachers, paying more attention to the cultivation of students' theoretical outstanding research capabilities, and other local colleges and universities in Guangxi conditions or general institutions often can not be compared, which determines we want to avoid these shortcomings in personnel training outstanding students practical skills. In short, the choice of the training model, we must not only play their strengths, but also see their own can not overcome disadvantages, and to the efforts of a clear direction, which is the essence of a concrete analysis of specific issues.

\section{CONCLUSIONS}

According to the training objectives, optimize curriculum, teaching content update, with the view of the system, the existing curriculum integration and innovation, build a new curriculum, adjusting knowledge structure. Curriculum system should fully reflect the knowledge, ability and overall quality of contemporary college students' require. Break the barriers between the curriculums, from the unity of the traditional course structure to comprehensive modern curriculum structure. We should increase courses of humanities, the emerging discipline and related disciplines, and arts, science, engineering interpenetrate each other, to adapt to the development and needs of modern society. We should change teacher-centered teaching in the past, teaching methods of teaching-based, and indoctrination. Then, we establish a student-centered thought, and reform teaching methods and means to fully mobilize the students' enthusiasm, initiative and creativity. We can individualize according to the characteristics of students. Introduction of new teaching methods heuristic, discussion, study type, practice type, etc, is to strengthen the modern teaching techniques and tools, such as the research and application of multimedia teaching. Reforming of teaching methods should be beneficial to students' motivation of learning, additionally, developing students' skills and innovative thinking will help the overall development of students' personality and talents.

\section{References}

[1] Cai Ni status quo in Guangxi Universities and Colleges in Beibu Gulf Economic Zone development [J] Qinzhou University, 2009,02: 56-59.

[2] Zhu Honghui Guangxi Beibu Gulf Economic Zone in Guangxi university development and talent training mode is missing [J] China Adult Education, 2009,23: 18-19.

[3] Liang Dyxun. research of reform of management system to improve the ability of achievements - economic development strategy based on scientific research Beibu Gulf

[4] Economic Zone in Guangxi College Transformation [J] Popular Science, 2012,03: 254-256 + 227.

[5] Mai Maosheng Universities of Applied Talents in Guangxi Beibu Gulf Economic Zone under cultivation strategies and countermeasures [J] Ankang University, 2012,03: 116-119 + 122.

[6] Lv Li Guangxi Universities of Applied Talents Cultivation of English skills - opening development strategy based on the Beibu Gulf Economic Zone [J] Hezhou University, 2011,03: 69-72.

[7] Zhu Honghui. Adapt personnel training mode Guangxi Beibu Gulf Economic Zone in Guangxi university development [J] China Adult Education, 2011, 18: 68-70.

[8] Guo Zhong-hua University Continuing Education in Guangxi Beibu Gulf Economic Zone to promote the development of research [J] Adult Education College of Hebei University, 2014,01: 36-39.

[9] Han Renjmei. Strategic thinking about talent training mode reform Guangxi Universities - Based on the Beibu Gulf Economic Zone Development of the new situation [J] heritage, 2008,24: 132-133. 